\title{
The Rhetorical Pattern of Script Defence Examination at Public Universities in Indonesia
}

\author{
Iskandar Abdul Samad \\ Syiah Kuala University \\ Aceh, Indonesia
}

\author{
Siti Sarah Fitriani \\ Syiah Kuala University \\ Aceh, Indonesia
}

\author{
Syamsul Bahri Yusuf \\ Syiah Kuala University \\ Aceh, Indonesia
}

\begin{abstract}
In many universities in Indonesia, script defence examination (SDE) is a must for students to graduate from their studies. The SDE is a compulsory unit that gives an opportunity for students to show their ability to understand the content of their research and to show their communicative competence. The SDE is considered as a genre which has its elements such as rhetorical pattern (RP). Understanding the RP could help students to perform competently in the SDE which ends with obtaining a high score. In literature, the information of RP of SDE is mostly available at the doctorate level. Consequently, the SDE RP of the undergraduate level could be important. This paper presents the SDE RP in public universities in Indonesia. To collect data, multiple observations in two public universities in Aceh and Medan were conducted. The SDE RP of these selected universities was determined and is presented in this paper.
\end{abstract}

Keywords—script defence examination; rhetorical pattern

\section{INTRODUCTION}

The script defence examination (SDE) is a compulsory unit at universities in Indonesia. Students are required to prepare themselves to perform competently in this event. Moreover, universities have provided at least two units, Research Methodology and Seminar Presentation, to prepare students to be competent in the SDE. Also, the script supervisors also help students in the script writing process. Students' understanding of the script content and rhetorical pattern (RP) as one of the elements of the SDE is essential. It is believed that their knowledge of these two aspects help them to perform competently and to obtain high mark.

In literature, the models of RP of the SDE have been found by researchers. However, the researchers focus on the doctorate level in the USA [1]-[4]. Another researcher Kirkpatrick \& Conlan has identified RP of seminar presentation between Indonesian and Australian students [5]. So far, the closest of SDE RP of this study can be seen in the work of Samad and Fitriani. In their research, they found RP of state Islamic universities in Aceh and Medan. This study can be considered as an extension of their research. However, this study aims at identifying RP of public universities from two state universities: Syiah Kuala University and the University of Medan. This study posed a research question: What is the RP of the SDE of public universities in Indonesia? The finding of the RP of these universities could enrich information regarding the RP in undergraduate level.
Furthermore, the RP could be used as a teaching material to prepare students to perform competently in the SDE [6].

\section{Methodology}

This study is a case study Yin and Nunan defines a case study as an investigation of a case or multiple cases to obtain in-depth information in the context in which the case occurs [8], [9]. This study focuses on RP of SDE in public universities in Indonesia. This RP seems to be forgotten from important aspects of the SDE.

\section{A. Data Collection}

This study was conducted in the English Education Departments (EEDs) of two selected universities. The data were collected through direct observations, interviews, notetaking, photo-taking, and video recording.

\section{B. Participant}

Seven examinees, five from Syiah Kuala University and two from University of Medan, were involved in this study. Their performance in presenting and defending their scripts were observed and analyzed.

\section{Data Analysis}

The data from the observations were analyzed using Swales (2004) model. Swales found four moves and some steps. Obligatory and optional steps are drawn in this RP [4]. The obligatory are those commonly found, while the optional are uncommonly found in the SDE.

\section{FINDING AND DISCUSSION}

\section{A. Syiah Kuala University (SKU)}

This section explains the RP which is derived from the SDE conducted by five students at SKU. The RP is identified from the observations and analysis of those students' performances. To keep the identity of the students confidential, all of them are given codes as SUE1, SUE2, SUE3, SUE4, and SUE5. Three segments were found at Syiar University; they are the preliminary, the opening and the defence proper. The details of the RP are presented: a) Preliminary segment: In this segment, there is only one activity found; that is all members prepared themselves ready 
for examination. The settling in of the SDE panel members is the only activity in this segment. These members, including the examiners, administration staff, and examinees, sat in the seats that had been allocated to them. Moreover, b) Opening segment. In this segment, there were three obligatory activities found: a. the head of the English Education Department (EED) officially opens the event; $b$. The examinees are asked to leave the room; c. The administration staff called the examinees in, one by one.

In the first activity, the head of the EED delivered a speech indicating that the SDE was officially opened. This formal speech was important at this university, because the SDE was an important event, and it could not commence if the official had not yet formally opened the ceremony. The degree of importance is seen from the rank of the officials who opens the event: the higher the status of the official, the greater the importance of the event. In the second act, all examinees were asked to leave the SDE room and to wait outside the TDE room for ten minutes before they were called back to perform in the examination. In the third act, the examinees were called back in by an administrator, one by one, to be tested by the examiners.

Defense proper segment. This segment consists of three obligatory activities: $a$. the examiners greeted the examinee; $b$. The examinee was asked to give a script presentation; $c$. The examiners asked questions freely to the examinees about the research project.

In the first activity, the majority of examiners greeted the examinees. The examiners enquired about the feelings of the examinees: whether or not they were happy having this examination. It was the examiners' strategy to address the examinees' anxiety. In the second activity, the examinee was asked to state the background of the research, research problems, and the findings, but it was very rare for examinees to mention the procedures used in their research. The third activity, the examiners, who were seated at a separate table, asked the examinees free questions. The questions were commonly related to the research topic. However, the significance of the research was rarely asked. Overlapping questions mostly occurred since the examiners sat at separate tables.

At SKU, the in-camera and the closing segments did not exist. However, the activity in-camera segment has occurred in the opening segment. The administration staff only announced to the examinees informally that the result would be finalized one month after the SDE, due to the large number of examinees undertaking the SDE.

\section{B. University of Medan (UM)}

This section presents the RP of the SDE which is drawn from the University of Medan. To identify the GS of the SDE, the data from two observations of two examinees' performances in the SDEs are used. These examinees are coded as UME1 and UME2 to keep the information confidential. The RP of the SDE at this university consists of five segments; these are preliminary, opening, defence, incamera, and closing.
Detailed information about the RP of the SDE at UM is discussed: a) Preliminary segment: This segment consists of one obligatory activity that is, The examiners, vice dean for academic affairs, a witness, a note taker and examinees settled in. In this segment, all members such as examiners, witness and note taker settled in. They were preparing for the SDE. All of them settled in while waiting for the vice dean for academic affairs, as he was an office staff to open the ceremony, b) Opening segment: In this segment, two speeches were given by civil servants, one was given by the vice dean for academic affairs, and another one was given by the head of English education department. The members and examinees listened to the speech given by these two officials. The content of the speech mostly motivates the examinees. These speeches are considered obligatory activities at this university, c) proper Defence segment. In this segment, the examinees were asked to conduct a research presentation, and it is followed by critical questions related to their research. Two activities found in this segment; one is obligatory, and the other is optional. The examinee is asked to conduct a research presentation. This activity is considered as optional. Only one of the two examinees conducted a research presentation. B. The examiners ask 'free' questions. This activity is obligatory. Asking free questions to the examinees may create overlapping questions. As a matter of fact, examiner one and examiner two asked a similar question which is the reason for choosing the research topic, and d) In-camera segment. This segment is the fourth segment. Two obligatory activities were found: 1) The examinee was asked to leave the room, and 2) A note taker calculated the examinee's score from the examiners. In the first activity, the examinees have been invited to leave the SDE room. While they were outside, each examiner was calculating the result and giving it to the note taker.

At this university, the closing segment is absent. The administration staff would announce the final result from note taker in a specified time.

\section{RHETORICAL PATTERN (RP) OF PUBLIC}

The RP of SDE of public universities in Indonesia consists of four moves: preliminary, opening, defence proper and incamera. In each segment, there are required, and optional activities found. Details information can be seen in the following table.

TABLE I. RHETORICAL PATTERN OF PUBLIC UNIVERSITIES IN INDONESIA

\begin{tabular}{|l|l|}
\hline \multicolumn{1}{|c|}{ SEGMENTS } & \multicolumn{1}{c|}{ ACTIVITIES } \\
\hline Preliminary & $\begin{array}{l}\text { The panel members: Deputy of Academic Affairs, } \\
\text { Head of Department examiners, examinees, } \\
\text { witness, note taker, settle in the room }\end{array}$ \\
\hline Opening & $\begin{array}{l}\text { Ceremony } \\
\text { [Greeting] } \\
\text { [examinees are asked to leave the room] }\end{array}$ \\
\hline Defence proper & $\begin{array}{l}\text { [Research presentation] } \\
\text { The examiners ask questions freely }\end{array}$ \\
\hline In-camera & $\begin{array}{l}\text { The examinee is asked to leave the room } \\
\text { The secretary or note taker calculate the score } \\
\text { from the examiners } \\
\text { The result is announced in a specified time }\end{array}$ \\
\hline
\end{tabular}


The activities written in brackets are optional. The RP of SDE shown in Table 1 is the common practice in these two selected universities. This information could help lecturers and students to perform competently in the SDE.

\section{CONCLUSION}

The SDE has genre elements, one of them is RP, which students are required to understand. Students are assumed to perform competently if they understand the RP. The identification of SDE RP at these two universities enriches information in the literature. The expansion of this research is encouraged for other researchers. Hence, the information is more fruitfully.

\section{References}

[1] A. D. Grimshaw, S. Feld, and D. Jenness, 'The multiple analysis project: Background, history, problems, data', Adv. DISCOURSE Process., vol.
43, p. 3, 1994.

[2] P. J. Burke, 'Segmentation and control of a dissertation defense', $A d v$. DISCOURSE Process., vol. 43, p. 95, 1994.

[3] R. Hassan, 'Situation and the Definition of Genres": In A. Grimshaw,(ed.) What's going on here? Complementary studies of Professional talk. Noxwood'. NJ.: Ablex Publishing, 1994.

[4] J. Swales, Research genres: Explorations and applications. Ernst Klett Sprachen, 2004.

[5] A. Kirkpatrick and C. Conlan, 'Information sequence structure in seminar discussions: a comparative study of Indonesian and Australian students in academic settings.' 2000.

[6] I. A. Samad and S. S. Fitriani, 'Genre element of script defence examination (SDE) of State Islamic Universities in Indonesia', in Proceedings of English Education International Conference, 2016, vol. 1, no. 2, pp. 95-99.

[7] R. K. Yin, 'Case study research, 4th'. Thousand Oaks, CA: Sage, 2009.

[8] D. Nunan, Research methods in language learning. Cambridge University Press, 1992.

[9] R. K. Yin, Case study research: Design and methods. Sage publications, 2013. 